\title{
Música e política em Jean-Jacques Rousseau: da teoria da unidade de melodia à vontade geral
}

\author{
Daniela de Fátima Garcia ${ }^{1}$
}

\begin{abstract}
Resumo: Tradicionalmente, são os textos ligados diretamente aos temas de moral, política e educação os que mais chamaram a atenção de comentadores e estudiosos para a filosofia de Jean-Jacques Rousseau. No entanto, parece ter sido a música um dos assuntos que mais ocupou os pensamentos do autor genebrino ao longo de toda sua vida. Sendo assim, o pensamento musical aparece não apenas como ideia inspiradora, mas antes, como própria referência teórica que compartilha dos mesmos princípios que irão fundamentar também seu pensamento político: para nosso autor, são as faculdades naturais do homem, que se traduzem em sentimentos e afetos originais, presentes antes do atual estado de corrupção moral, que dão expressividade à música, tanto quanto significado e coesão às instituições políticas.
\end{abstract}

Palavras-Chave: Rousseau - Música - Política - Afetos - Unidade de melodia - Vontade geral

\section{Music and Politics in Jean-Jacques Rousseau: from the theory of melody unity to the general will}

\begin{abstract}
Traditionally, it is texts directly linked to the themes of morals, politics and education that have most drawn the attention of commentators and scholars to the philosophy of Jean-Jacques Rousseau. However, music seems to have been one of the subjects that most occupied the thoughts of the genebrine author throughout his life. Thus, musical thinking appears not only as an inspiring idea, but rather as a theoretical reference that shares the same principles that will also base his political thinking: For our author, it is the natural faculties of man, his feelings and affections that give expressiveness to music, as much as meaning to political institutions.
\end{abstract}

Keywords: Rousseau - Music - Politics - Affections - Melody unity - General will.

\footnotetext{
${ }^{1}$ Doutoranda Filosofia da Universidade Federal de São Paulo (Unifesp). E-mail: dani.f.garcia@gmail.com. Orientadora: Prof ${ }^{a}$. Dr ${ }^{a}$. Jacira de Freitas. Este artigo foi composto durante a pesquisa atual de doutorado que conta com financiamento da Capes, a qual agradeço o apoio.
} 
Rousseau criticava o conhecimento livresco e o "saber" filosófico e se considerava um dissidente entre os philosophes, apesar de ter compartilhado da efervescência cultural na qual viviam os enciclopedistas. A autoimagem de Rousseau parece contradizer os fatos: desde o prêmio e o consequente sucesso obtido pelo Discurso sobre a ciência e as artes, que o autor ganha uma notoriedade no mundo das letras cuja tendência é aumentar, à medida que seus textos vêm a público ${ }^{2}$. O caráter ambíguo de Rousseau é reconhecido e expresso pelo próprio autor em seus textos autobiográficos. Nas Confissões, por exemplo, nos deparamos ora com um Rousseau pesaroso pelos rumos que sua carreira tomou, ora exaltado com seu próprio "sistema", ou entusiasmado com a recepção de suas obras junto aos leitores, como no caso de $A$ Nova Heloísa.

Mas, em meio às "contradições" de Rousseau, o que se constata é um tom diferenciado quando se trata da temática musical. Ao narrar sua primeira experiência com a música, Rousseau já nos deixa uma indicação da associação entre o prazer auditivo e os movimentos da alma, por exemplo, na alegria que sente ao ouvir a tia cantar "com um fiozinho de vOz muito suave", cantigas que lhe ficarão na memória. A experiência mnemônica parece se fixar usando como recurso a qualidade moral da "serenidade da alma dessa excelente moça". ${ }^{3}$

Assim, no decorrer das Confissões, as memórias relativas à música vão surgindo, sempre associadas ao prazer, aos momentos de felicidade espontânea e afetos sinceros. A nostalgia da lembrança de suas primeiras experiências com a música aparece sempre relacionada a um estado de inocência original, de pureza do gosto relacionado à pureza de alma, de plenitude e verdadeira comunhão. Longe de se configurar como simples divertissement, a música aparece como a própria referência para o resgate da sensibilidade e espontaneidade perdidas, lugar da experiência subjetiva, distante da corrupção e degeneração presentes em Paris. A música, assim, juntamente com a botânica, se apresenta para Rousseau como uma espécie de locus amoenus, lugar privilegiado onde é possível se locomover ou, mais acertadamente, fixar seu verdadeiro lugar, com certa segurança. Desejando paz e tranquilidade, Rousseau se refugia em seu trabalho de copista de música.

Sua autobiografia é indicativa, Rousseau parece querer nos deixar um recado: a música foi, ao longo de sua vida, sua paixão mais verdadeira e original. E, se nosso autor confessa não se sentir "bastante sábio", nem achava em si mesmo "bastante espírito para brilhar na república das letras", considerava-se suficientemente competente em música para empreender carreira na área, tanto que foi esse desejo que o leva a se instalar em Paris no início da década de 1740. Wokler nos lembra que:

Como a maioria dos homens mais insignes na república das letras de seu mundo, Rousseau, evidentemente, tinha muitos outros interesses além da política. Era um compositor admirado e autor de um extenso dicionário

\footnotetext{
2 Veja MATOS, “Outra versão das Luzes”, in PIMENTA, Pedro Paulo (org.) Rousseau - Escritos sobre a Política e as Artes, que traça a polêmica em torno da publicação do Primeiro Discurso, e lembrando as demais polêmicas nas quais Rousseau se envolveria, o que faz de nosso autor "um dos mais formidáveis polemistas do século das Luzes", e uma celebridade ainda em vida no mundo das letras.

${ }^{3}$ ROUSSEAU, Confissões, p. 34.

${ }^{4}$ ROUSSEAU, Confissões, p. 257.
} 
musical de grande erudição, e a música talvez tenh a sido o assunto que mais lhe ocupon a atenção ao longo da vida. ${ }^{5}$

Rousseau trabalhou no referido dicionário, o seu Dicionário de Música, por duas décadas, aperfeiçoando os verbetes sobre música que escreveu para compor os volumes da Enciclopédia. Enquanto ia escrevendo obras como o Contrato Social e o Emilio, nunca deixou de se interessar pelas teorias musicais, realizando pesquisas contínuas na área, estabelecendo seus próprios princípios e compondo o que poderíamos chamar de seu pensamento musical.

O Dicionário de Rousseau, não apenas condensa todo o saber musicológico da época, mas ao demonstrá-lo, Rousseau ainda viabiliza as noções estéticas musicais para superá-lo. Por meio da exaltação de certas características presentes na música, como a relação entre música e língua e a preferência dada à melodia em detrimento da harmonia, Rousseau rompe com os padrões estéticos-musicais de seu tempo, deixando ainda referências estéticas para as próximas gerações de músicos. ${ }^{6}$

Com todas essas indicações podemos afirmar, com um certo grau de certeza, que as ideias musicais de Rousseau sempre prefiguraram em seu pensamento. Bernard Gagnebin nos chama a atenção para a sonoridade de sua prosa, onde o autor se revelaria um músico completo:

Harmoniosa, musical, ritmada, sua linguagem testemunha uma preocupação musical constante. Considere-se o Livro VI das Confissões, onde ele evoca a alegria das Charmettés, ou o Livro VII, onde ele relata suas impressões venezianas. Sempre ampla, frequentemente periódica, sua frase é rica em valores sonoros. Dos diversos sentidos, Rousseau privilegia a audição.

Rousseau nos parece, assim, antes músico do que filósofo e John T. Scott confirma: "Os escritos musicais e composições de Rousseau não são, portanto, uma parte isolada de sua obra, mas um importante aspecto de sua filosofia", visto que "os mais importantes escritos musicais de Rousseau são contemporâneos de seus maiores trabalhos filosóficos, e a descoberta do sistema que ele elaborou em seus trabalhos filosóficos também o leva a repensar e desenvolver sua teoria musical e integrá-la em sua filosofia como um todo."

Rousseau, portanto, não poderia querer expressar através de sua filosofia o que gostaria de ter feito por meio da música? Acaso os princípios que estabeleceu para a música formaria um sistema completamente a parte de sua filosofia? Indagamos assim, se seus textos sobre música estariam totalmente desvinculados do restante de sua obra ou, ao contrário, formariam com ela um todo unívoco e indissociável, nos indicando inclusive outras perspectivas de aproximação e análise da filosofia do genebrino. Sendo assim, qual seria o

\footnotetext{
5 WOKLER, Rousseau, p.13. Grifos nossos.

${ }^{6}$ Afirma Fubini: "Rousseau, autor de muitas entradas sobre música da Encyclopédie (mais tarde reunidas no Dictionnaire de musique) foi o filósofo da música mais original do grupo dos Enciclopedistas e as suas teorias sobre a união originária da música com a linguagem tiveram imenso sucesso na França e não só; serão retomadas e desenvolvidas no Romantismo, embora com contornos diversos e à margem da velha polémica entre fautores do melodrama italiano e do melodrama francês, por Herder, Harnann, Schlegel e, ainda, por Nietzsche e Wagner." FUBINI, Estética da música, p. 120.

${ }^{7}$ GAGNEBIN, Introduction aux Écrits sur la musique, la langue et le théatre, p. XXVIII.

8 SCOTT, "Rousseau and the Melodious Language of Freedom”, p. 804.
} 
vínculo teórico que manteria a relação entre as concepções musicais de Rousseau e outros temas abordados em suas obras?

Nosso objetivo, portanto, no presente trabalho é o de verificar a existência dessa ligação teórico-conceitual entre os vários temas abordados por Rousseau em sua obra, iniciando com a noção de uníssono musical, nos concentrando em seguida em alguns aspectos de sua teoria sobre a origem das línguas e finalizando com o conceito de vontade geral. Retomaremos, assim, três textos de Rousseau que, em um primeiro momento, podem até aparentar não terem relação significativa entre si. Trata-se da Carta sobre a Música Francesa, que condensa uma expressão acabada do pensamento musical de Rousseau; o Contrato Social que, por sua vez, expressa uma versão acabada de sua teoria política; e o Ensaio sobre a Origem das Linguas, no qual encontramos uma expressão unificada entre sociedade, linguagem e música, onde "a relação entre música e política encontra sua forma mais filosoficamente desenvolvida". ${ }^{\circ}$

\section{A melodia}

Foi durante a Querela dos Bufões, uma das mais notáveis contendas musicais da história, que Rousseau vê a ocasião propícia para tornar pública sua Carta sobre a música francesa. Estrategicamente inserida num debate que moveu a opinião da maior parte do público frequentador dos espetáculos franceses, letrados e leigos, a Carta de Rousseau conquista a antipatia da sociedade parisiense para seu autor, ao defender a música italiana em detrimento da música francesa ${ }^{10}$. Mas, se a sociedade parisiense se sente ofendida em seus sentimentos patrióticos, a contenda que a Carta suscita com o compositor Jean-Philippe Rameau adquire um caráter teórico muito mais denso e complexo. Em sua Carta, Rousseau expõe sua teoria da unidade de melodia que, em termos estéticos, significa uma contrapartida ao sistema harmônico de Rameau ${ }^{11}$.

Entende-se que a Carta de Rousseau pode ter sido escrita anteriormente à querela, excetuando-se apenas alguns acréscimos incluídos posteriormente com o intuito de situar seu texto dentro do debate. Desse modo, de acordo com Oliver Pot $^{12}$, se considerarmos a Carta por essa perspectiva de criação, a querela teria sido usada como pretexto para apresentar ao público as teses mais gerais e reflexões mais teóricas que já estavam sendo elaboradas, tomando consistência e formando o que se poderia chamar de pensamento sobre música na filosofia de Rousseau. Ainda segundo Pot:

(...) a Carta sobre a Música Francesa teria reunido pela primeira vez, por ocasião de um problema secundário colocado pela polêmica, duas grandes

\footnotetext{
9 MARQUES, "Rousseau, Rameau e o Ensaio sobre a Origem das Línguas". Disponível em: unicamp.br/ jmarques/pesq/ensaio.htm (Acesso em 15/06/2020).

${ }^{10} \mathrm{Em}$ meu artigo "Rousseau contra a música francesa" faço uma breve análise dos argumentos expostos por Rousseau em sua Carta, que o leva a defender a música italiana. No mesmo artigo exponho ainda, brevemente, como o autor da Carta retoma temas já tradicionais nos debates sobre música, atribuindo-lhes um significado próprio ao torná-los compatíveis com sua própria filosofia.

11 O leitor pode encontrar uma excelente análise da querela estética entre Rousseau e Rameau na tese de doutorado de Fábio Yasoshima, Entre o canto das paixões e os artifícios da harmonia: o pensamento musical de Rousseau contra o sistema harmônico de Rameau.

12 POT, "Introducion à Lettre sur la Musique Française", OC, V, p. XCIX-CXXXVI.
} 
orientações do pensamento de Rousseau, a saber: de uma parte, a análise linguística que fundamenta a prioridade da melodia, reflexão mais recente e ainda inédita que faz sua aparição por meio da comparação entre a língua italiana e a língua francesa; e, de outra parte, um corpo de digressões já conhecidas pelos artigos publicados ou a publicar na Encyclopédie. ${ }^{13}$

De fato, ao escrever os verbetes de música para a Encyclopédie, Rousseau já tem bem elaborado e definido o conjunto de sua doutrina musical, cujo principal princípio se encontra na primazia da melodia sobre a harmonia. Esse ponto de vista estético adotado por Rousseau é geralmente aceito enquanto tendência a abalar os fundamentos do sistema harmônico de Jean-Philipe Rameau, como afirma O’Dea “estes artigos constituem um corpo sistemático da doutrina anti-ramista, e um documento precioso sobre a evolução do pensamento de Rousseau, dois anos antes da redação do Discurso sobre as ciências e as artes" "14. Constata-se, assim que as preocupações teórico-musicais de Rousseau antecedem mesmo ao episódio da iluminação de Vincennes. ${ }^{15}$

A crítica de Rousseau à música francesa, assim como expressa na Carta, pode até assumir o formato de uma disputa musical já tradicionalmente instaurada, ou seja, a tentativa de comparação entre o estilo italiano e o francês ${ }^{16}$. Mas, ao se desdobrar em uma contra argumentação à teoria estética de Rameau, a crítica de Rousseau é capaz de emprestar à disputa um tom filosófico que está em perfeita conformidade com as teorias e teses que fundamentam sua própria filosofia. Quando Rousseau formula na Carta a teoria da unidade da melodia, o autor nos revela uma acurada análise linguística capaz de não só justificar esteticamente sua preferência pela música italiana, como fundamentar filosoficamente a expressividade musical:

Para que uma música se torne interessante, para que ela leve à alma os sentimentos que nela se quer excitar, é preciso que todas as partes concorram para fortalecer a expressão do tema; que a harmonia não sirva senão para torná-la mais enérgica; que o acompanhamento a embeleze sem a encobrir nem desfigurar; que o baixo, por uma marcha uniforme e simples, guie de certa forma aquele que canta e aquele que ouve, sem que nem um nem outro disso se apercebam. Em duas palavras: é preciso que o conjunto não leve ao mesmo tempo mais que uma melodia ao ouvido e mais que uma ideia ao espírito. ${ }^{17}$

\footnotetext{
13 POT, "Introducion à Lettre sur la Musique Française", OC, V, p. CVI.

14 O’DEA, "Rousseau contre Rameau: musique et nature dans les articles pour l'Encyclopédie et au-delà", p. 145.

${ }^{15}$ No Livro VIII das Confissões podemos conferir a descrição da comoção de Rousseau ao ler, no Mercure de France, a proposta da Academia de Dijon para a premiação do ano seguinte, que faz nosso autor ver um outro universo e tornar-se um outro homem com uma espécie de antevisão profética de seu próprio sistema.

16 Remeto o leitor ao meu artigo "Rousseau contra a música francesa", no qual faço uma breve exposição sobre alguns pressupostos teóricos que antecedem a Querela dos Bufões. As questões envolvendo a comparação entre os estilos de ópera francesa e italiana têm origem já nas primeiras apresentações no início do século XVII, envolvendo extensa bibliografia. GARCIA, "Rousseau contra a música francesa", Anais do SEFiM, V. 3, n. 3, p. 21-36, 2017.

${ }_{17}$ ROUSSEAU, Carta sobre a música francesa, p. 21. Grifos nossos.
} 
O que Rousseau busca enquanto beleza musical, se define por uma única linha melódica que seja a referência capaz de garantir a transparência e a clareza na expressividade dos sentimentos. Como conseguir isso? Fazendo com que os demais elementos da música, harmonia e ritmo, sigam fielmente essa linha melódica, o que o autor chama de "acompanhamento em uníssono".

A questão do uníssono na teoria musical de Rousseau é significativo. As vozes, cantando juntas, produzindo uma única melodia, entram em concordância quanto ao afeto, ao sentimento que se deseja expressar. Essa concordância interna entre as vozes, unidas em torno de um mesmo afeto, não só expressam com toda a clareza o sentimento desejado, numa comunicação clara e imediata que se traduz em beleza musical, mas é a própria beleza musical que se traduz em ordem e coerência, em concordância e unanimidade. Nota-se também que o referencial do uníssono em Rousseau não está relacionado apenas à união entre as vozes que formam um só canto. Com uníssono, nosso autor também se refere à correspondência perfeita entre a orquestra e o canto, à concordância entre a linha melódica do canto e o acompanhamento instrumental.

A noção de uníssono, como apresentada na Carta, nos chama a atenção para a ênfase que nosso autor confere à ideia de coerência interna da composição. Por esse motivo, a teoria melódica de Rousseau preza pelo poder da unidade, da coerência interna, da perfeita comunhão entre as partes, deixando claro os sentimentos que se deseja expressar. Assim, nosso autor vê na música mais do que um agregado de notas que se sucedem, ou se sobrepõem, uma após a outra, sem estabelecerem qualquer relação significativa entre si, ou sustentando apenas uma relação de conveniência. Isso porque clareza expressiva depende menos da quantidade e complexidade de sons do que da relação que estabelecem entre si. Cada elemento da composição, cada nota ou cada voz, acorde ou movimento, tem seu papel bem específico determinado em função do todo, do conjunto, da unidade. Nenhuma nota pode ser dissonante do todo, nenhuma voz pode se destacar em detrimento das outras, e o acompanhamento não pode se sobrepor ao som da voz, nem discordar dela. A noção de unidade, então, se traduz nessa coerência interna que se torna perceptível pela beleza do conjunto, da harmonia entre as partes que concordam todas com a mesma finalidade que é a de comunicar o tema afetivo.

O efeito imediato dessa proposta estético-musical de Rousseau é a exaltação do canto, elemento sobre o qual recai todo o poder expressivo da música que, em decorrência direta, dependerá das características próprias de cada língua:

Já afirmei que toda música nacional extrai seu principal caráter da língua que lhe é própria, e devo acrescentar que é principalmente a prosódia da língua que constitui esse caráter. Como a música vocal precedeu em muito a instrumental, esta última sempre recebeu da primeira sua maneira de entoar e seu ritmo, e os diversos ritmos da música vocal só puderam nascer das diversas maneiras pelas quais é possível escandir o discurso e dispor as palavras breves e as longas umas em relação às outras. ${ }^{18}$

${ }^{18}$ ROUSSEAU, Carta sobre a música francesa, p. 10. 
As características próprias de cada língua, regulando a disposição entre sílabas longas e breves, fornece sonoridade à música, conferindo-lhe suas propriedades mais aprazíveis. Além da sonoridade, é a língua que carrega propriamente o conteúdo expressivo da música pelas marcas das paixões que traz em si, como Rousseau exemplifica por meio da música italiana:

Ela é doce porque suas articulações são pouco complexas, porque o encontro de consoantes é nela raro e sem aspereza, e porque, dado que um grande número de sílabas é formado apenas por vogais, as frequentes elisões tornam sua pronúncia mais fluente; ela é sonora porque a maior parte das vogais é brilhante, porque não possui ditongos compostos, quase não tem vogais nasais, e porque as articulações esparsas e fáceis distinguem melhor o som das sílabas, que se torna mais nítido e mais cheio. ${ }^{19}$

Vogais sonoras e abundantes, poucas consoantes, sílabas de pronúncia marcante e clara, seriam elementos que, estando presentes na língua na qual o canto é composto e executado, proporcionariam à melodia fluidez, leveza, espontaneidade e simplicidade. Notase também que, mesmo quando a voz não está presente na música, é devido à sua entonação específica que se pode compor música instrumental, que não seria mais que um prolongamento da voz humana.

Em termos estéticos e filosóficos, Rousseau se afasta do universo conceitual, que é dado pelo significado convencional das palavras e notas musicais, e se aproxima da pura expressividade, excluindo a intermediação dos signos. Na via diametralmente oposta, a música de Rameau, apoiada sobre uma teoria mecanicista, mediada, portanto, por um racionalismo cientificista ${ }^{20}$, só pode vincular como reflexo de todo um conjunto de elementos que rendem homenagens ao artificialismo, à falta de expressividade e à falsidade das convenções que regem as relações humanas. A complexidade dos ornamentos e a profusão de notas da música de Rameau, mostra-se para Rousseau apenas como o produto acabado de uma ordem política e social que é representativa da falta de liberdade e sensibilidade que nosso autor constata em sua época.

Para Rousseau, o poder expressivo da voz humana não pode ser contestado, por ser o próprio fundamento que enseja a origem da música e da língua. Está, portanto, na origem hipotética que Rousseau constrói para a música e a língua a própria referência filosófica para se bem julgar a música em sua força expressiva, como observa Salinas:

Quanto maior a proximidade da origem, mais elevada será a posição ocupada na escala hierárquica dos valores expressivos. A música será, nessas condições, a forma expressiva por excelência, a quintessência da expressividade. E, por isso mesmo, o modelo ideal, o paradigma dos paradigmas, a ideia do perfeito realizada sensivelmente a guiar, como estrela polar, as outras formas de expressão e em especial a arte da escrita. ${ }^{21}$

\footnotetext{
${ }^{19}$ ROUSSEAU, Carta sobre a música francesa, p. 14.

${ }^{20}$ Entre as várias acepções filosóficas que o termo razão e racionalismo podem apresentar, me refiro aqui especificamente ao racionalismo cartesiano.

${ }^{21}$ SALINAS FORTES, Paradoxo do espetáculo: política e poética em Rousseau, p. 84.
} 
Retomemos, então, à hipótese da origem para rever em seus fundamentos essa relação essencial entre música e língua, e como dela derivam as diferenças entre as músicas nacionais, dadas pela melodia da voz e dos sentimentos originais que modulam as diferentes línguas.

\section{As bases afetivas}

Para Rousseau, música e língua surgem simultaneamente, se fundindo enquanto uma mesma forma expressiva que emerge espontaneamente da necessidade do homem em fazer comunicar seus sentimentos. Tal necessidade surge no momento mesmo em que o homem passa a reconhecer no outro um ser semelhante. Como podemos ler no Ensaio sobre a origem das línguas: "Não se começou por raciocinar, mas por sentir"22, sendo a própria história das origens narrada por Rousseau a testemunha dessa necessidade premente de expressividade afetiva, como constata Starobinski:

Os poços em torno dos quais os jovens encontram outros jovens são o cenário idílico de uma ópera fabulosa onde Rousseau faz representar o despertar do amor - condição, enfim, suficiente para o surgimento da língua primitiva (...). A fábula, assim narrada em uma linguagem ela mesma rítmica e acentuada, faz da linguagem melodiosa original a expressão da unidade do prazer e do desejo, a verdade manifesta do sentimento interior. ${ }^{23}$

$\mathrm{Na}$ origem descrita por Rousseau, a condição necessária para o surgimento das línguas é a da sobrevivência que, sendo despertada por condições físicas exteriores, faz com que os homens se reúnam em grupos. No entanto, a necessidade puramente física de sobrevivência não é suficiente para fazer com que os homens reunidos se comuniquem. O desejo intrínseco no homem de transmitir aos seus semelhantes suas paixões e sentimentos é que faz com que crie os meios efetivos e eficientes de comunicação e expressão. É, portanto, a uma causa moral que Rousseau atribui a "invenção" da língua e da música.

Necessidades físicas e necessidades morais são dois termos frequentes no Ensaio e nos remetem a dois tipos de relações estabelecidas pelo homem nesta fase de transição do estado natural para o social: a relação estabelecida entre o homem e a natureza, e a relação que os homens estabelecem uns com os outros. Aprendemos com Rousseau ${ }^{24}$ que as necessidades físicas nos remetem ao homem enquanto ser isolado, gozando de liberdade natural, independente dos outros homens quanto aos meios para conseguir seu alimento e se reproduzir, suas únicas fontes de preocupação. Se dependesse apenas de sua vontade, o homem continuaria indefinidamente desfrutando de seu natural estado de indolência. É preciso que a natureza aja sobre o homem e, frente às adversidades naturais que colocam sua sobrevivência em risco, os homens são levados a se agruparem a fim de compartilhar da água

22 ROUSSEAU, Ensaio sobre a origem das linguas, p. 296.

23 STAROBINSKI, "Introduction à l'Essai sur l'Origine des Langues", OC, V, p. CLXXXVII.

${ }^{24}$ Como se sabe, no Discurso sobre os fundamentos e origem da desigualdade entre os homens, Rousseau traça mais marcadamente esta passagem do estado natural para o social, compondo uma descrição completa das características do homem natural e suas faculdades inatas. 
ou do fogo ${ }^{25}$. Nesta ocasião de primeiro contato, que ocorre sem que os homens exerçam de fato sua vontade, sendo apenas impulsionados por uma necessidade que lhes é externa, o homem então passa a perceber ${ }^{26}$ o outro enquanto um ser semelhante. Como bem constata Barbara Guetti ${ }^{27}$, portanto, o comportamento instintivo não depende da fala, apenas o comportamento social a faz surgir. Nas palavras do próprio Rousseau:

Em torno das fontes de que falei, os primeiros discursos foram as primeiras canções. O retorno periódico e cadenciado do ritmo, as inflexões melodiosas dos acentos, trouxeram à luz a poesia e a música, juntamente com a língua, ou antes, tudo isso era a própria língua, mesmo nos climas e tempos venturosos em que as únicas necessidades prementes que exigiam a colaboração alheia eram as engendradas pelo coração. ${ }^{28}$

Se na Carta sobre a música francesa Rousseau afirma que uma música para ser agradável e bela deve estar próxima dos nossos sentimentos naturais, nosso autor se refere evidentemente não ao estado primitivo do homem enquanto ser isolado, mas a esse instante "mítico" do surgimento das línguas, enquanto forma expressiva musicada, que marca o início da sociedade. Trata-se, portanto, de uma sociedade primária que empreende seus primeiros rudimentos culturais, e essa língua primitiva melodiosa se estabelece assim enquanto a primeira instituição social.

A voz da natureza que Rousseau reclama para a música é, então, oriunda de um estado de sociedade primitivo. $\mathrm{E}$ as paixões originais que essa língua musicada transmite assim o são, à medida que correspondem às primeiras reações, fruto da imaginação e do contato com o semelhante. Elas significam o primeiro movimento dentro do estado de sociedade nascente e expressam toda a pureza e espontaneidade dessa sociedade primitiva ainda isenta de corrupção.

Se o canto e a fala, a música e a língua, são formas de expressividade da vida anímica que se confundem nessa comunicação primitiva mas ainda espontânea, no decorrer da evolução social, as perspectivas e necessidades dos homens mudam alterando as formas de comunicação. Com o processo de desenvolvimento das sociedades, principalmente no que se refere ao aspecto comercial, as línguas e a música se transformam em duas possibilidades distintas de expressão, coexistindo em uma relação de reciprocidade, como salienta Guetti ${ }^{29}$, nem sempre harmoniosa. Rousseau aponta o aperfeiçoamento da língua, ou seja, sua precisão e rigor gramatical, como o principal fator responsável pela separação entre língua e música. Conforme o homem evolui em suas instituições sociais "a língua torna-se mais exata, mais clara, porém mais lânguida, mais surda e mais fria" ${ }^{30}$. Esse aperfeiçoamento é visto por Rousseau como negativo do ponto de vista estético, pois enquanto as línguas, evoluindo,

\footnotetext{
${ }^{25}$ Recomendo o artigo de DELA BANDERA, "Origem e alteração no pensamento linguístico-musical de Rousseau", no qual o leitor encontra uma excelente exposição sobre a tese geral da formação das línguas em Rousseau em contraposição à tese das diferenças entre a formação das línguas do Sul e do Norte.

26 A questão da percepção na filosofia de Rousseau envolve todo um processo de mudanças nas faculdades inatas e originais, transformando-as de passivas ou inativas em ativas e atuantes. No presente artigo não vemos a conveniência de desenvolver tal questão dado o espaço que a tarefa exigiria.

${ }^{27}$ GUETTI, “The double voice of nature: Rousseau's Essai sur l'origine des langues".

${ }^{28}$ ROUSSEAU, Ensaio sobre a origem das linguas, p. 332.

${ }^{29}$ GUETTI, "The double voice of nature: Rousseau's Essai sur l'origine des langues".

${ }^{30}$ ROUSSEAU, Ensaio sobre as origens da lingua, p. 300.
} 
ganham em precisão conceitual, perdem ao mesmo tempo suas belezas naturais e seu potencial expressivo. Rousseau, assim, aponta diretamente para a relação existente entre a decadência da pronúncia e o progresso da escrita, que se encontra inseparável da corrupção moral e política ${ }^{31}$. Quem perde é a força expressiva da voz, sufocada pela violência das coisas, como tão bem definiu Bento Prado.

A música, então, em sua relação direta com a língua, é sintomática desse estado de coisas, sendo o elemento que melhor acusaria o grau de liberdade do qual desfrutaria o povo de uma determinada nação, tal como Rousseau o mostra no Capítulo XX do Ensaio: "Existem línguas propícias à liberdade; são as sonoras, prosódicas, harmoniosas, cujo discurso se distingue de longe. As nossas são feitas para os conchavos palacianos."32

\section{A vontade geral}

Tentamos deixar evidente que a afetividade não ocupa apenas o lugar central na teoria musico linguista de Rousseau, ela é o motivo mesmo de seu surgimento. Se o mundo propriamente humano, da sociedade e cultura, tem início devido à necessidade expressiva de compartilhamento dos afetos, é possível compreender por que o vazio emotivo nas formas de expressão e a ausência da comunicação sincera e imediata a ele relacionada, revelaria a medida da perda de liberdade de uma comunidade política, o que se constata pela crítica de Rousseau à música francesa.

Mas, se o vazio expressivo e a comunicação truncada estão relacionados com a perda da liberdade, como sintomas da corrupção moral de seu tempo, Rousseau já bem o evidencia na denúncia expressa no Discurso sobre as ciências a as artes:

E assim a dissolução dos costumes, efeito necessário do luxo, traz por sua vez a corrupção do gosto. Se porventura se encontre, entre os homens que se destacam por seus talentos, alguém que tenha firmeza de alma para recusar-se a fazer concessões ao gênio de seu século e a aviltar-se com produções pueris, ai dele! Morrerá na indigência e no esquecimento. ${ }^{33}$

O gosto se rende aos interesses egoístas, à adulação e ao luxo desnecessário, e a rigorosa crítica à música francesa formulada na Carta encontra seu fundamento moral no Primeiro Discurso. Prova de que a música não é matéria de interesse menor na filosofia do genebrino, muito ao contrário. Devido mesmo à sua intrínseca relação com a língua e ao surgimento da sociedade, a música tem a característica de ser permeável ao modelo moral, reflexo do nível de corrupção da sociedade. Quando Rousseau faz ruir a ilusão da música francesa no teor crítico da Carta, complementa por meio do seu pensamento teórico musical

\footnotetext{
31 O leitor pode consultar o artigo de RIBEIRO, "Linguagem e política: Rousseau leitor de Charles Duclos", para uma exposição mais completa sobre a relação entre o desenvolvimento da escrita e a corrupção dos governos, assim como a influência que o Remarques sur la Grammaire Générale et Raisonée de Charles Duclos exerceu sobre essa teoria de Rousseau.

32 ROUSSEAU, Ensaio sobre a origem das línguas, p. 352. Optamos pela tradução do Ensaio de Pedro Paulo Pimenta in Rousseau - Escritos sobre a Política e as Artes, por ir de encontro aos esclarecimentos de Lucas Mello Carvalho Ribeiro sobre o sentido da palavra "divan" no texto rousseauniano. Veja RIBEIRO, "Linguagem e Política: Rousseau leitor de Charles Duclos".

${ }^{33}$ ROUSSEAU, Discurso sobre as ciências e as artes, p. 56.
} 
a denúncia moral do Primeiro Discurso: as formas de comunicação e expressão já não são mais autênticas, transparentes, mas estão a serviço de interesses particulares. Ora, os interesses particulares ecoam como notas dissonantes que quebram com a noção de uníssono, necessária para se compor uma sociedade harmoniosa.

O quadro, então, parece pessimista: fala-se, mas já não é mais possível se fazer entender e a voz que canta já não é mais a do coração, mas a do interesse. A pergunta de Rousseau se torna pertinente: "Nos tempos antigos, quando a persuasão tinha lugar de força pública, a eloquência era necessária. De que ela serviria hoje, quando a força pública supre a persuasão?"34 Sobre a citada passagem de Rousseau, Bento Prado nos aponta que "A violência não remete mais à pré-humanidade, ao grau zero da História; ao contrário, ela é seu produto mais refinado." ${ }^{35}$

Diante de tal estado de coisas, seria ainda possível tentar resgatar os afetos originais dos primeiros tempos que se faziam expressar pela força da voz e mediação das palavras? O homem perdeu, de fato, sua natureza original, ou trata-se de uma natureza que está apenas oculta sob o véu das aparências? Questão pertinente já proposta por Starobinski. ${ }^{36} \mathrm{O}$ grito original da natureza pode ter sido abafado pela imposição da frieza gramatical na precisão da escrita, por outro lado, alguma coisa dessa natureza ainda pode ser recuperada. Prova disso é a música italiana que ainda traz algo da originalidade dos primeiros acentos emotivos. Para Rousseau, a música, sem dúvida, opera como um dos meios pelos quais a expressividade afetiva adquire voz. Mas a voz que deseja cantar expressando seus afetos não é a mesma que clama por soberania e liberdade? Não seria, então, a vontade geral, um duplo da unidade da melodia, ambas tentativas de enaltecer a expressividade da voz e a comunicação dos afetos originais?

Vejamos no Contrato Social como Rousseau se refere à vontade geral: "Cada um de nós põe em comum sua pessoa e todo o seu poder sob a direção suprema da vontade geral, e recebemos, enquanto corpo, cada membro como parte indivisível do todo". ${ }^{37}$ Com o advento do contrato, o indivíduo isolado já não existe mais. Não é mais possível conceber um sujeito individualmente, de forma independente da sociedade. ${ }^{38}$ Se, para Rousseau, como vimos, as notas musicais tocadas ao acaso e individualmente não formam uma composição, assim são igualmente os indivíduos após o início da sociedade: só existem em função do todo, enquanto sujeitos morais nas relações que estabelecem uns com os outros:

Imediatamente, esse ato de associação produz, em lugar da pessoa particular de cada contratante, um corpo moral e coletivo, composto de tantos membros quantos são os votos da assembleia, e que, por esse mesmo ato, ganha sua unidade, seu eu comum, sua vida e sua vontade. ${ }^{39}$

\footnotetext{
${ }^{34}$ ROUSSEAU, Ensaio sobre a origem das linguas, p. 352.

35 PRADO JR., A Retórica de Roussean e outros ensaios, p. 110.

36 STAROBINSKI, $A$ transparência e o obstáculo, p. 29.

37 ROUSSEAU, Do Contrato social, p. 33. Termo complexo que causa ainda bastante divergência entre os comentadores. Apresentamos no presente texto uma breve análise do conceito de vontade geral, apenas para fins de adequação ao objetivo presente.

${ }^{38}$ Veja ROUSSEAU, Do Contrato social, p. 33, nota 61.

39 ROUSSEAU, Do Contrato social, p. 33.
} 
A ideia de unidade e da coerência interna dessa unidade é a referência sem a qual não é possível pensar nem a música, nem a sociedade. Tanto na composição da comunidade política quanto na composição musical, é a noção do todo, do conjunto, da relação harmoniosa entre as partes, que se constitui enquanto ponto central ordenador.

O desafio, portanto, consiste não apenas em buscar e manter essa coerência interna do todo, mas mais do que isso, fazer com que esse todo se movimente de maneira não apenas ordenada, mas harmoniosa, em concordância, em outras palavras, em concerto. Kawauche nos chama a atenção para a identificação da noção de concerto no Contrato com aquela de uma assembleia de músicos em uma orquestra, sendo definida como um rearranjo de forças "tal que o somatório delas seja coerente em direção a um único fim, com cada força concorrendo para um mesmo objetivo e com todas as partes relacionando-se harmoniosamente dentro do conjunto" 40 .

Podemos entender, concordando com Kawauche, que a correspondência entre a noção de concerto e acordo nos remete à noção de uníssono. No Contrato a ideia de uníssono aparece na forma do ajuste das forças e interesses individuais às regras de conduta e ao bem comum que se traduz na vontade geral. ${ }^{41}$ Por meio da vontade geral, portanto, transparece a noção de uníssono e da força da voz, capaz de impor uma direção ao corpo político. Com uma certa conotação estética, a vontade geral é o que concebe movimento ao corpo político, não apenas de uma maneira bem ordenada, mas, antes, harmoniosa, visando o bem comum:

(...) só a vontade geral pode dirigir as forças do Estado de acordo com a finalidade de sua instituição, que é o bem comum, porque, se a oposição dos interesses particulares tornou necessário o estabelecimento das sociedades, foi o acordo desses mesmos interesses que o possibilitou. O que existe de comum nesses vários interesses forma o liame social e, se não houvesse um ponto em que todos os interesses concordassem, nenhuma sociedade poderia existir. ${ }^{42}$

A vontade geral opera, assim, enquanto elemento aglutinador, tal qual a voz melodiosa do canto que engendra em torno de si, e a partir de si, a coerência interna da composição. Semelhante à tirania das notas que se acumulam umas sobre as outras, cada qual tentando se sobressair acima das demais, como ocorre na música francesa, um único interesse particular que pretenda se elevar acima das outras vontades, torna-se uma nota dissonante fora do comum acordo da comunidade.

Resta-nos esclarecer o que fundamenta essencialmente a autoridade da vontade geral enquanto expressão do bem comum. Embora o contrato seja fruto do artifício, "desnaturando" o homem de seu estado original de independência para fazer dele um ser em relação, ou seja, um ser cuja existência passa a depender das relações sociais estabelecidas, algo

\footnotetext{
${ }^{40}$ KAWAUCHE, “O concerto dos homens: sobre a relação entre natureza e sociedade em Rousseau”, p. 248.

${ }^{41}$ KAWAUCHE, "O concerto dos homens: sobre a relação entre natureza e sociedade em Rousseau”, p. 250.

42 ROUSSEAU, Do Contrato Social, p. 43.
} 
de sua natureza deve ser preservado. Acaso não seria o Emílio uma tentativa de fazer do homem social um ser tão íntegro quanto possível em sua própria natureza original?33

No Discurso sobre a origem e os fundamentos da desigualdade entre os homens Rousseau nos traça o perfil do homem natural e, como se sabe, a pitiè, ou piedade, constando entre as faculdades inatas, é aquela que nos permite a identificação com o outro. De acordo com Derathé, a piedade estaria na base da própria sociabilidade: "a única forma de sociabilidade que Rousseau admite ou, antes, a única que lhe parece natural é aquela que tem seu fundamento na identidade de nossa natureza sensível." ${ }^{44}$

Vimos no Ensaio sobre a Origem das Linguas que embora o apelo à sobrevivência dê o primeiro impulso para que os homens se agrupem, esse agrupamento, no entanto, não pode ser chamado de sociedade se não houver bases afetivas sobre as quais se sustentar, bases essas dadas pelo sentimento de identidade adquirido por meio da pitiè. Nas Cartas escritas da montanha lemos: "Todas as instituições humanas são fundadas nas paixões humanas e se conservam por meio delas" $"$.

Os afetos e o sentimento de identificação que surgem nesses primeiros tempos de sociedade, oriundos da capacidade de ver o outro como um ser semelhante, é que devem ser vistos enquanto verdadeiro liame da sociedade. Se a funcionalidade do Contrato se apresenta de uma forma um tanto quanto mecânica, não se pode deixar de considerar que cada um dos membros da comunidade se encontra envolvido com os demais por afinidades afetivas que preservam os sentimentos originais de afeição mútua, levando cada um dos membros a interesses similares, tornando possível o acordo que rege a vontade geral. São esses afetos ainda que estabelecem a correspondência necessária entre expressividade, língua, música e sociedade. Como afirma John T. Scott: "Os cidadãos de uma verdadeira comunidade se comunicam imediatamente e em uma só voz devido às paixões compartilhadas. Eles compartilham não apenas costumes, moralidade e opiniões em comum, mas também uma língua e música comum." 46

Se a comunicação imediata e transparente não é possível, a vontade geral não pode se efetivar. Numa legítima comunidade política, as opiniões não apenas concordam, mas compartilham entre si interesses afins, paixões em comum. A coerência da unidade não precisa ser imposta por uma vontade estranha porque ela flui harmoniosamente, pois as vontades convergem espontaneamente e com liberdade para um mesmo objetivo. Nesse contexto os indivíduos são cidadãos, se sentem cidadãos. Essa noção de cidadania não é um conceito vazio, adquire significado que pode ser expresso por meio da música, pois são partes constituintes de uma unidade. São integrantes de uma verdadeira comunidade política, porque suas vozes podem expressar livremente as vontades de seus corações.

\footnotetext{
43 Veja MATOS, Rousseau - uma arqueologia da desigualdade: "A distinção entre o homem natural e o homem social faz aparecer a "natureza" como um absoluto - o homem natural não poderia ser destruído no interior do homem social - de outra maneira a educação do Emílio seria impossível”, p. 30.

${ }^{44}$ DERATHÉ, Rousseau e a ciência politica de seu tempo, p. 227.

${ }^{45}$ ROUSSEAU, Cartas escritas da montanha, p. 170.

46 SCOTT, "Rousseau and the melodious language of freedom", p. 804. Foi originalmente este artigo de John T. Scott que me revelou a perspectiva analítica que exponho no presente trabalho e que desenvolvo em minha pesquisa. Devo, portanto, a John T. Scott todo o crédito pela ideia de relacionar música e política na filosofia de Rousseau sob a perspectiva do fundamento das bases afetivas.
} 


\section{Referências bibliográficas}

BANDERA, Mauro Dela. "Origem e alteração no pensamento linguístico-musical de Rousseau”. In: Cadernos de Ética e Filosofia Política, V. 1, n. 36, pp. 138-161, 2020.

DERATHÉ, Robert. Jean-Jacques Rousseau e a Ciência Política de seu Tempo. Trad. de Natalia Maruyama. São Paulo: Editora Barcarolla/Discurso Editorial, 2009.

FUBINI, Enrico. Estética da música. Lisboa: Edições 70, 2008.

GAGNEBIN, Bernard. "Introduction aux Écrits sur la musique, la langue et le théâtre”. In: ROUSSEAU, Jean-Jacques. CEuvres complètes. Volume V. Paris: Éditions Gallimard, 1995, p. XIII-XXIX.

GARCIA, Daniela F. A música sob a perspectiva crítica de Rousseau: uma análise da Carta sobre a Música Francesa. (Dissertação de Mestrado em Filosofia) - Universidade de Campinas, Faculdade de Filosofia e Ciências Humanas, Campinas, 2008.

GARCIA, Daniela F. "Rousseau contra a música francesa”. In: Anais do SEFIM, V. 3, n. 3, pp. 21-36, 2017.

GUETTI, Barbara J. “The double voice of nature: Rousseau's Essai sur l'origine des langues”. In: MLN, Vol. 84, n. 6, Comparative Literatura, Johns Hopkins University, pp. 853-875, Dec., 1969.

KAWAUCHE, Thomaz. "O concerto dos homens: sobre a relação entre natureza e sociedade em Rousseau”. In: Princípios, Natal, v. 17, n. 27, jan/jun 2010, p. 243-254.

MATOS, Olgária. Rousseau - uma arqueologia da desigualdade. São Paulo, M.G. Editores, 1978.

O’DEA, Michaël. "Rousseau contre Rameau: musique et nature dans les articles pour l'Encyclopédie et au-delà'. In: Recherches sur Diderot et sur l'Encyclopédie, n. 17, pp. 133148, 1994.

PIMENTA, Pedro Paulo (org.) Rousseau - Escritos sobre a politica e as artes. Traduzido por Pedro Paulo Pimenta... [et al.]. São Paulo: Ubu Editora, 2020.

POT, Oliver. "Introducion à Lettre sur la Musique Française". In: ROUSSEAU, JeanJacques. Euvres Complètes, Volume V. Paris: Éditions Gallimard, 1995, p. XCIX-CXXXVI.

PRADO JR, Bento. A retórica de Rousseau e outros ensaios. Organização e apresentação Franklin de Matos. São Paulo: Editora Unesp, 2018.

RIBEIRO, Lucas Mello C. "Linguagem e política: Rousseau leitor de Charles Duclos". In: Cadernos de ética e filosofia política, v. 1, n. 34, p. 143-152, 25 jun. 2019.

ROUSSEAU, Jean-Jacques. CEuvres complètes, Volume V : Écrits sur la musique, la langue et le théâtre. Paris: Gallimard, 1995. 
. "Do contrato social; Ensaio sobre a origem das línguas; Discurso sobre a origem e os fundamentos da desigualdade entre os homens; Discurso sobre as ciências e as artes". In: Os Pensadores. São Paulo: Abril Cultural, 1978.

Cartas escritas da Montanha. Trad. e notas de Maria Constança Peres Pissara... [et al.]. São Paulo: EDUC/Editora Unesp, 2006.

Carta sobre a música francesa. Tradução e notas de José Oscar de Almeida Marques e Daniela de Fátima Garcia. Campinas: IFCH-Unicamp, 2005 (Textos Didáticos, 58).

. Confissões. Tradução de Raquel de Queiroz e José Benedicto Pinto. Bauru: Edipro, 2008.

SALINAS FORTES, Luiz Roberto. Paradoxo do espetáculo: politica e poética em Rousseau. São Paulo: Discurso Editorial, 1997.

SCOTT, John T. "Rousseau and melodious language of freedom". In: The Journal of Politics, Vol. 59, no 3, Chicago: The University of Chicago Press, Aug., p. 803-829, 1997.

STAROBINSKI, Jean. A transparência e o obstáculo, seguido de Sete ensaios sobre Rousseau. São Paulo: Companhia das Letras, 1991.

"Introduction à l'Essai sur l'Origine des Langues". In: ROUSSEAU, Jean-Jacques. CEuvres complètes, Volume V. Paris: Éditions Gallimard, 1995, p. CLXV-CXCVII.

WOKLER, Robert. Rousseau. Porto Alegre: L\&PM, 2012.

YASOSHIMA, Fábio. Entre o canto das paixões e os artifícios da harmonia: o pensamento musical de Rousseau contra o sistema harmônico de Rameau. Tese (Doutorado em Filosofia) - Faculdade de Filosofia, Letras e Ciências Humanas da Universidade de São Paulo, São Paulo/SP, 2017. 